\title{
COMPARISON BETWEEN BOTTOM AND SIDE INJECTION OF BENTONITE SLURRY IN TREATMENT OF SAND DUNES
}

\section{Al-Maghrabi M. H.; Aboushook, M.I; Fadol, Abbas and Abdelhaffez, Gamal}

Mining Engineering Department, Faculty of Engineering, King Abdulaziz University, Jeddah, Saudi Arabia Email: profdraboushook@gmail.com

(Received July 28, 2009 Accepted November 24, 2009).

Movement of sand dunes in the Arabian Peninsula hinder land development, expansion of city limits, and cause hazard in paved roads across arid areas. Population growth and environmental construction have been harmed by these sand dune blunders. Sand dunes stabilization has been the concerns of many government agencies and academic institutions. Many researches have contributed various methods to counter the sand dunes movement. Some of these researches have used agriculture scheme to attain stabilization. Such project requires continuous supply of water and needs several years to realize its objective. Lack of careful monitoring or a shortage of water supply would rapidly degrade the stabilization process, and sand dunes eventually bounce back to uncontrolled movement and desertification. Other researchers opted for chemical and polymers components as stabilization agents. It stabilizes only the top surface of the sand dunes. A moderate air draft/ gust of air would erode the top cover and thus frees the underneath sand dunes to move unrestrained/ uncontrolled. Additionally, using chemical and polymers components are not environmentally advocated.

This research is a first part of competent research program studying different methods of sand dunes treatment using bentonite ore which are: mixing\& compaction with bentonite powder and slurry; surface and subsurface spraying of bentonite slurry; bottom and side injection of bentonite slurry.

This study has used the non- active calcium bentonite ore coming from khulais region, Saudi Arabia. This deposit has a very big reserve near to the surface and it is not used as commercial product until now and it is a natural clay deposit and has an ability to bind the sand grains and to conserve water for very long time. The stabilization process by this proposed method is not only on the surface of sand dunes but also to some depths from surface. That is to provide a relative thick bed on the sand dune surface that has the ability to resist wind blew and erosion. In addition, it is able to conserve water for very long time.

This paper deals with the comparison between bottom and side injection of bentonite slurry in sand treatment. The method which used bottom injection gives some improvement in engineering properties of sand dunes. Their values increased to (3.5-4.0) times the original values compared with only (1.0-1.50) times the original values in the case of using side injection. These values have been obtained after 30 days of the 
treatment and using only $1 \%$ of bentonite concentration compared with 5 years after traditional treatments.

\section{مقارنة بين الحقن من أسفل ومن جوانب كعب الحقن

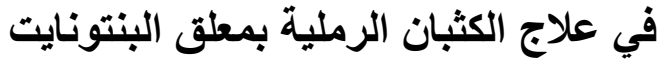

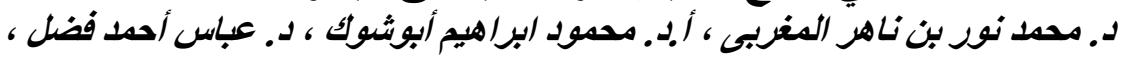

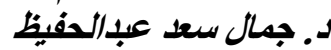

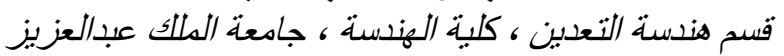 \\ profdraboushook@gmailcom}

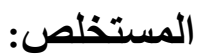

تتسبب الكثبان الرملية المنتشرة في معظم أراضى شبه الجزيرة العربية بمخاطر كبيرة على البيئة السكانية

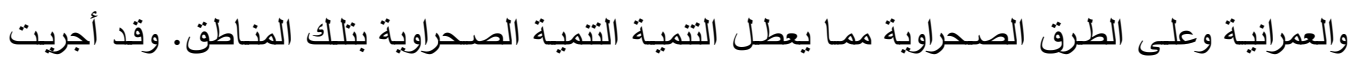

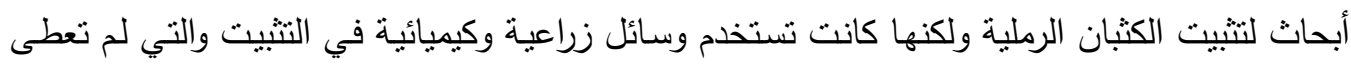
نتائج ملموسة للاستمرار في استخدام تلك الوسائل من الناحية الاقتصادية والبيئية وطول مدة العـلاج خاصة للوسائل الزراعية.

وهذا البحث مستخرج من المرحلة الثالثة لبرنـامج بحثي مترابط يتتـاول دراسـة الطرق المختلفة لعـلاج الكثبان الرملية باستخدام خام البنتونايت وهى: طريقة الخلط والدمك بمسحوق ومعلق البنتونايت ، طريقة الرش السطحي والتحت السطحي بمعلق البنتونايت، طريقة الحقن من أسفل ومن جوانب كعب الحقن بمعلق البنتونايت.

وفى تلك الدراسة يتم استخدام خام البنتونايت الكلسى الخامل في علاج الكثبان الرملية لبس فقط للعلاج

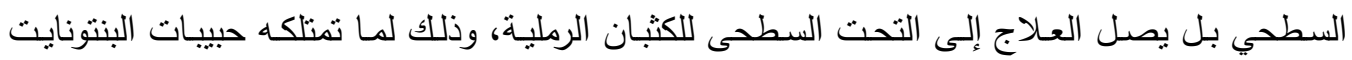

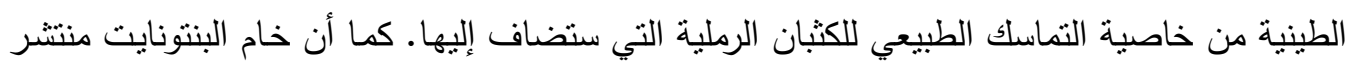
بوفرة بمعظم المناطق الصحراوية الجافة وهو غير مستغل اقتصاديا نظرا لعدم فاعليته في النشاطات

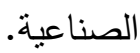

وقد تمت المقارنة في هذا البحث بين نتائج الحقن من أسفل ومن جوانب كعب الحقن بمعلق البنتونايت

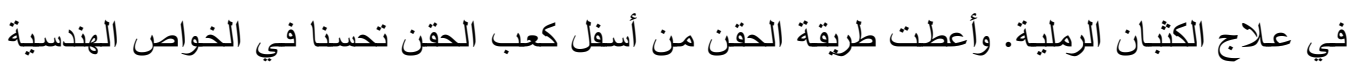

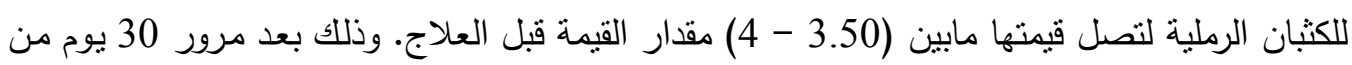
العلاج وبتركيز 1\% فقط في معلق البنتونايت.

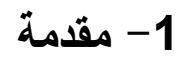


تغطى الكثبان الرمليـة مسـاحات شاسـعة في العـالم وهى تثـكل خطرا كبيـرا في شبه الجزيـرة العربيـة لانتشارها حول الددن والقرى وشبكات الطرق والمزارع ومصادر المياه والري والمراعى. ورغم الجهود التي

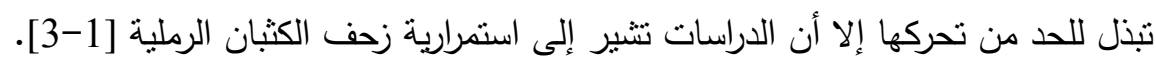

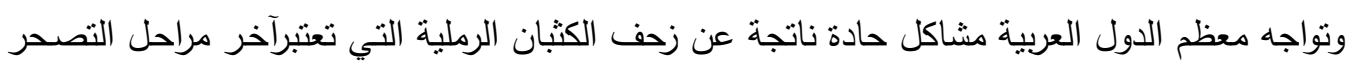

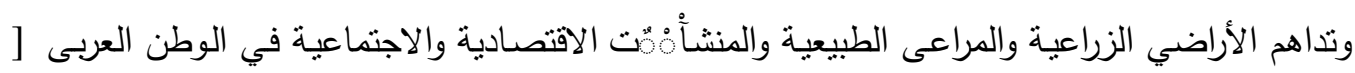

وتعتبر العوامل المناخية أهم العوامل البيئية التي تؤثر على النظام البيئي وتجعل منه نظاما بيئيا حساسا

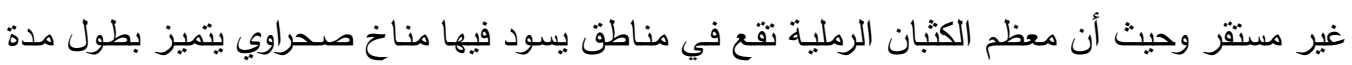

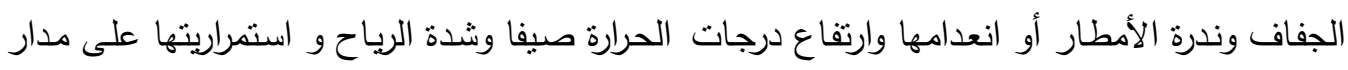
السنة.

ويتميز مناخ شبهه الجزيرة العربية بأنه صحراوي وشبه صحراوي ترتفع فيه درجة الحرارة صيفا إلى ما

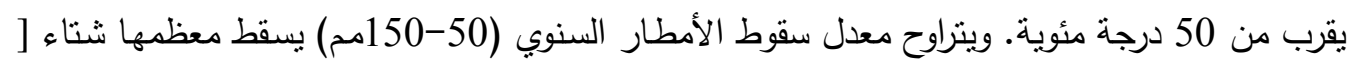
.[10-5

ونظرا للمشاكل الكبيرة التي تنجم عن حركة الكثبان الرملية وذلك بتهديدها المستمر للمنشآت الصناعية

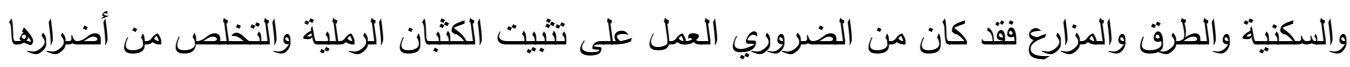

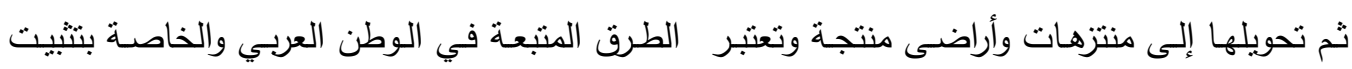

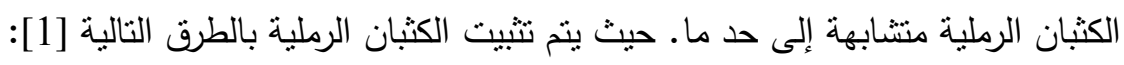

أ- إقامة الحواجز الأمامية والدفاعية كخطوط أولى أمام زحف الرمال.

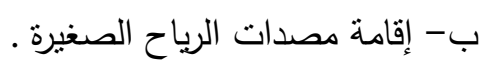
ج- تغطية الكثبان الرملية بالآتي: - المواد النباتية الميتة.

-المشتقات النفطية والمواد الكيميائية أو المطاطية أو الطينية.

-تشجير الكثبان الرملية بنباتات مناسبة لوسط الكثبان الرملية.

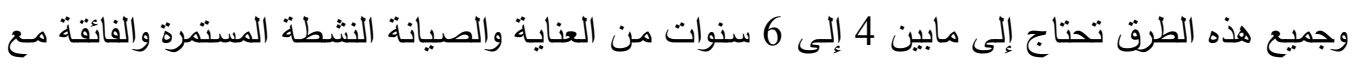

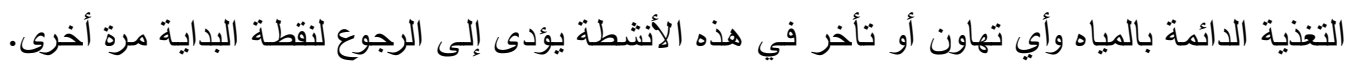

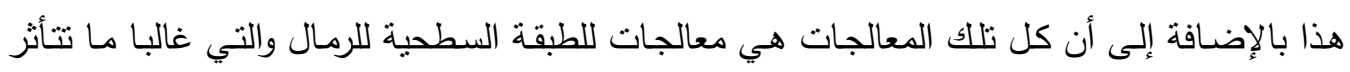
وتتهار في حالة هبوب رياح قوية ومن اتجاهات مختلفة. وفى هذا البحث سيتم العلاج للطبقة تحت السطحية للرمال بحيث تتحول إلى طبقة من الرئ الرمال المنماسكة القادرة على مقاومة الرياح العاتية. 


\section{2- التجارب المعملية}

1-2 الخواص الطبيعية لخام البنتونايت الكلسى الخامل تم تعيين الخواص الطبيعية التالية للعينة الممثلة من خام البنتونايت الخايت الخامل والآتي من منطقة خليص بمنطقة مكة المكرمة طبقا للمواصفات القياسية [2]: - دلبة محتوى الطين

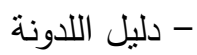

- كمية الصبغة الزرقاء لكل 1جم.

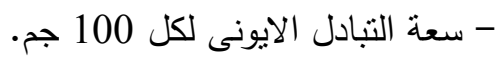

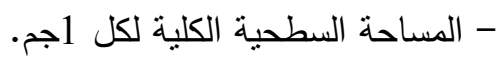

وتتضح نلك النتائج بالجدول رقم (1) ، ومنها يتبين أن نشـاط الانتفاخ والتماسك لمعادن الطين بخام

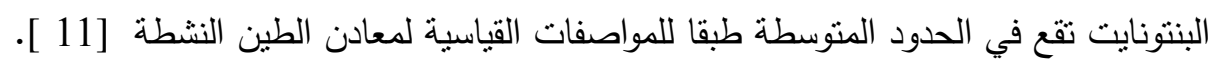

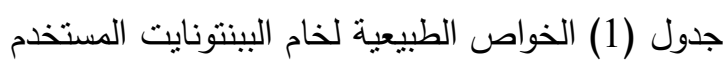

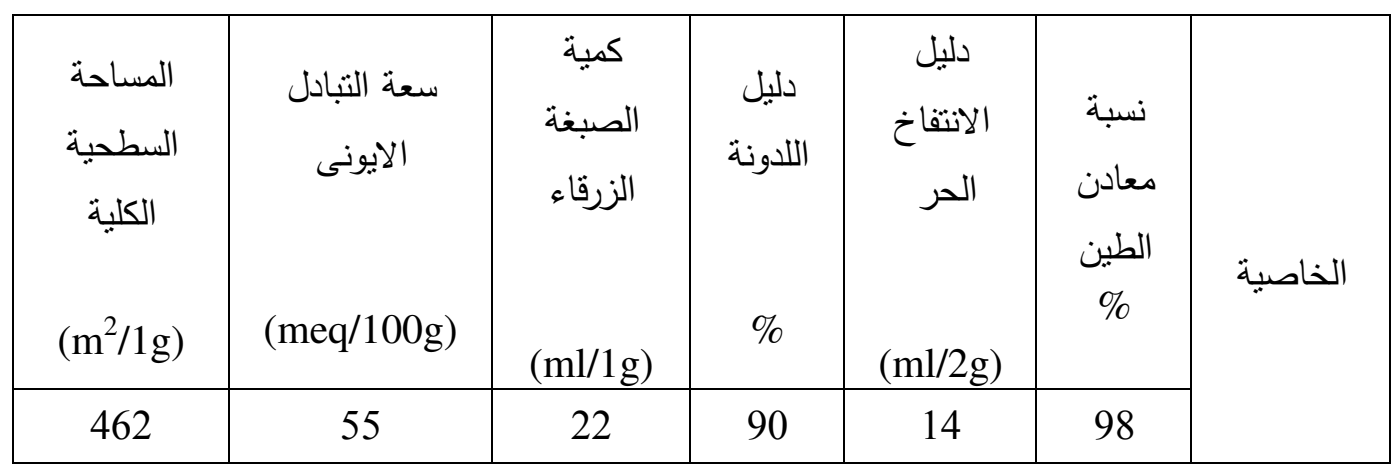

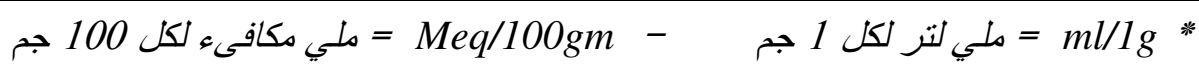

\section{2-2 الخواص الطبيعية للكثبان الرملية}

تم قياس دليل الكثافة الحقلية لطبقة الكثبان الرملية تحت السطحية وذلك بواسطة حساب عدد الدقات اللازمة لاختراق 4سم من مسمار مشرشر من الصلب ذو قطر اسم داخل طبقة الرمل وذلك باستخدام مندلة صغيرة ذات نقل 0.5 كجم. 
وتتضح نتائج تلاك القياسات بالجدول رقم 2 ، حيث يتضح أن عدد دقات الاختراق لموقع الكثبان يتراوح من 5 إلى 7 دقة لكل 4 سم. وقد تم تتفيذ تلك التجارب الحقلية بغرض تجهيز العينات المعملية عند ظروف متقاربة أو متشابهه مع الظروف الحقلية وبنفس التقنية [12 ].

وقد تم عمل التحليل المنخلي لعينة من الكثبان الرملية والتي تتضح نتائجها بالجدول رقم 2. حيث يتبين منها مدى شدة نعومة حبيبات الكثبان الرملية.

جدول (2) نتائج التجارب الحقلية والخواص الطبيعية للكثان الرملية

\begin{tabular}{|c|c|c|c|c|}
\hline \multicolumn{2}{|c|}{ التوزيع الحيبي } & \multicolumn{3}{|c|}{ الخواص الحقلية } \\
\hline 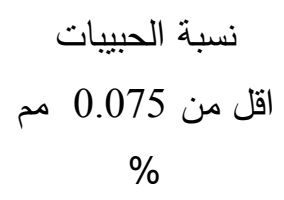 & نسبة الحبييات & نسبة الرطوبة & جثافة & الاختراق " عدد دقات \\
\hline 2.00 & 98.00 & $5-3.5$ & 1.70 & $7-5$ \\
\hline
\end{tabular}

* عدد الدقات اللازمة لاختراق 4 سم من مسمار صلب مشرشر ذو قطر 1 سم داخل طبقة الرمل

\section{2-3 خواص الدمك للكثبان الرملية}

نم تتفيذ عدد من تجارب الدمك على الكثبان الرملية الغير مختلطة بالبنتونايت وذلك للوصول إلى أنسب الظروف فى الحصول على نتائج متشابهة أو منقاربة مع نتائج التجارب الحقلية المذكورة أعلاه وهى 5 - 7 دقة لكل 4 سم. وقد تم تثبيت نسبة الرطوبة الابتدائية لعينات الدمك عند 7 \% والتي لتئي لاتبعد كثيرا عن مثيلتها في الحقل وذللك لضمان تجانس وتماسك العينات المعطلية. ومن ثم تم دمك العينة على ثلاث

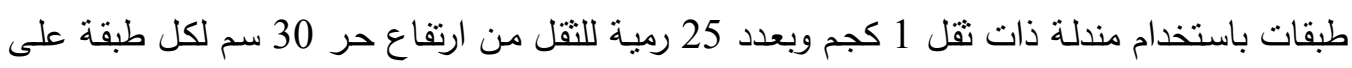
حده بغرض الوصول إلى نتائج منقاربة مع نتائج القياسات الحقلية. ويبين الجدول رقم 3 النتائج التي تم الحصول عليها في هذا الثأن [13- 16 ].

جدول (3) نتائج التجارب المعملية لدمك الكثبان الرملية

\begin{tabular}{|c|c|c|c|c|}
\hline الكثافة الجافة & نسبة الرطوبة & عدد الرميات & عدد الطبقات & عدد دقات \\
\hline القصوى & المتلىى & لكل طبقة & اللازمة & الاختراق \\
\hline
\end{tabular}




\begin{tabular}{|c|c|c|c|c|}
\hline 3 & $\%$ & & & \\
\hline 1.60 & 7 & 25 & 3 & 7 \\
\hline
\end{tabular}

\section{2-4 الخواص الهندية قبل ويعد معالجة الكثبان الرملية}

تم قياس الخواص الهندية التالية للكثبان الرملية قبل وبعد العلاج وفى أزمنة مختلفة (3 ، 10 ، 30

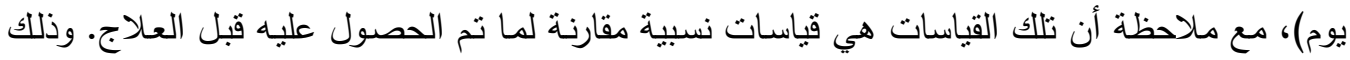

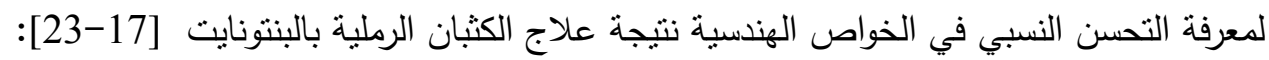

أ- مقاومة الغزز

تم قياس مقاومة الغرز باستخدام مقياس الغرز القياسي المستخدم في مجال الهندسة الجيوتقنية والذي يعبر عن مقاومة الرمل للضغط الحر والمقدرة بالكيلوبسكال.

ب- مقاومة الاخترلق تم قياس مقاومة الاختراق بحساب عدد الدقات اللازمة لاختراق 4 سم من مسمار مشرشر صلب ذو قطر

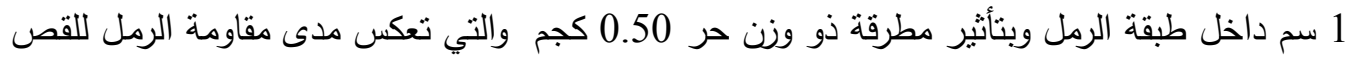

$$
\text { جـ- أقصى سرعة للهواء المؤثثر }
$$

تم قياسها باستخدام ضاغط هواء منصل بمقياس لكمية وسرعة الهواء المؤثرة على الكثبان الرملية وذلك بإحداث حفرة بعمق 3 مم في الكثبان الرملية وهى تعبر عن مدى استقرار الكثبان الرملية.

\section{4- طريقتى الحقن من أسفل ومن جواتب كعب الحقن بمعلق البنتونايت}

نظرا لصعوبة تتفيذ حقن البنتونايت داخل الكثبان الرملية، نم إعداد وتجهيز معلق البنتونايت بتركيزات

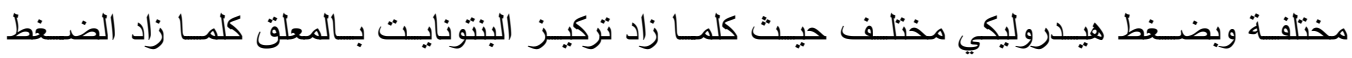
الهيدروليكى اللازم لحقن المعلق داخل الكثبان الرملية. ويقصد بالحقن من أسفل كعب الحقن بأن يتم تصريف معلق البنتونايت فقط من أسفل كعب الحقن. أما لها الحقن من جوانب كعب الحقن فإنه يتم تصريف معلق البنتونايت من جوانب كعب الحقن فقط. وقد تم استخدام كعب واحد فى منتصف قالب العينة. والذي ينكون من قالب اسطواني بقطر 12 سم وارتفاع 6

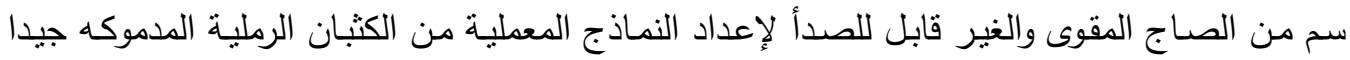
حتى تتشابهة كثافتها مع كثافة الكثبان الرملية بالموقع. وتم قياس الخواص الهندية الثلاثة وهى مقاومة الاختراق وعدد دقات الاختراق والسرعة المؤثرة عند التركيزات المختلفة للبنتونايت في المعلق وبالتالي عند مستويات ضغوط هيدروليكية مختلفة وكذللك بعد 
مرور أزمنة مختلفة لطريقتي الحقن. وتتضح نتائج نلك الخواص بالجداول (4 ، 5) وبالأشكال (1 - 9 جدول (4) الخواص الطبيعية الابتدائية لعينات كثبان الليث في حالة استخدام طريقة حقن البنتونايت

\begin{tabular}{|c|c|c|}
\hline 5.00 & $\%$ & نسبة الرطوبة الابتدائية \\
\hline 1.57 & طن/منز 3 & الكثافة الجافة \\
\hline 72 & $\%$ & نسبة الفراغات \\
\hline 42 & $\%$ & المسامية \\
\hline
\end{tabular}

جدول (5) الخواص الهندية لكثبان الليث بعد العلاج بحقن البنتونايت أ- الحقن من أسفل الكعب

\begin{tabular}{|c|c|c|c|c|c|c|c|c|c|c|c|}
\hline \multicolumn{3}{|c|}{ أقصى سرعة مؤثرثرة } & \multicolumn{3}{|c|}{ عدد دقات الاخترلق } & \multicolumn{3}{|c|}{ مقاومة الغرز } & \multirow{4}{*}{ سمد3/ معدل } & \multirow{4}{*}{ الهيدروليكي الضغي } & \multirow{4}{*}{ في البنتونايت تركيز } \\
\hline بعد & بعد & بعد & بعد & بعد & بعد & بعد & بعد & بعد & & & \\
\hline 30 & 10 & 3 & 30 & 10 & 3 & 30 & 10 & 3 & & & \\
\hline يوم & يوم & يوم & يوم & يوم & يوم & يوم & يوم & يوم & & & \\
\hline 0 & 0 & 10 & 0 & 0 & 5 & 0 & 0 & 15 & 200 & 0.25 & 0 \\
\hline 22 & 32 & 12 & 22 & 20 & 6 & 45 & 50 & 17 & 120 & 0.50 & 0.25 \\
\hline 27 & 39 & 15 & 30 & 23 & 8 & 75 & 60 & 20 & 12 & 1.00 & 0.5 \\
\hline 60 & 53 & 20 & 40 & 37 & 10 & 100 & 80 & 35 & 3.5 & 1.50 & 1 \\
\hline
\end{tabular}

جدول (5) الخواص الهندسية لكثبان الليث بعد العلاج بحقن البنتونايت ب- الحقن من جوانب الكعب

\begin{tabular}{|c|c|c|c|c|c|c|c|c|c|c|c|}
\hline \multicolumn{3}{|c|}{ (كقصى سرعة مؤثرة } & \multicolumn{3}{|c|}{ عدد دقات الاخترلق } & \multicolumn{3}{|c|}{ مقاومة الغرز } & \multirow{4}{*}{ سمد3/دقرف } & \multirow{4}{*}{ الضيدروليكى } & \multirow{4}{*}{ 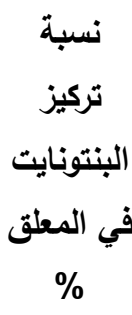 } \\
\hline بعد & بعد & بعد & بعد & بعد & بعد & بعد & بعد & بعد & & & \\
\hline 30 & 10 & 3 & 30 & 10 & 3 & 30 & 10 & 3 & & & \\
\hline يوم & يوم & يوم & يوم & يوم & يوم & يوم & يوم & يوم & & & \\
\hline 0 & 0 & 10 & 0 & 0 & 5 & 0 & 0 & 15 & 220 & 0.25 & 0 \\
\hline 30 & 25 & 11 & 11 & 13 & 5 & 5 & 10 & 15 & 100 & 0.50 & 0.25 \\
\hline 35 & 36 & 12 & 9 & 14 & 5 & 10 & 20 & 17 & 40 & 1.00 & 0.5 \\
\hline 25 & 39 & 15 & 9 & 15 & 5 & 10 & 30 & 20 & 5 & 1.50 & 1 \\
\hline
\end{tabular}

ومن تلك النتائج يتضـح أن طريقـة الحقن من أسفل الكعب أعطت نتائج أفضل بكثير في تحسين الخواص الهندسية للكثبان الرملية، حيث أنه تم تسجيل انخفاض سريع وملموس في قيم التحسن في 
الخواص الهندسية المقاسة بعد مرور 30 يوم من الحقن من جوانب الكعب بالنسبة لما تم قياسه بعد 10

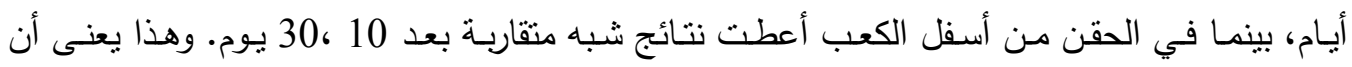
البنتونايت الذي تم حقنه باستخدام الحقن من أسفل الكعب انتشر في جميع طبقات جسم الكثبان مقارنة

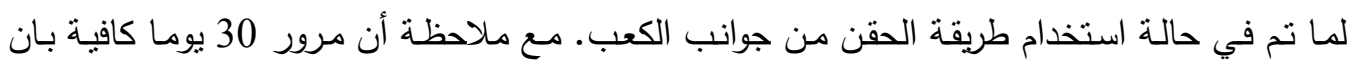

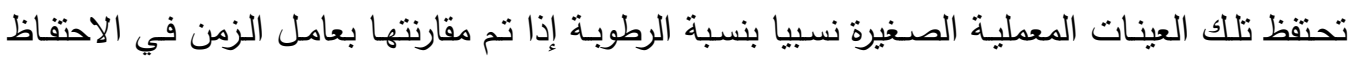

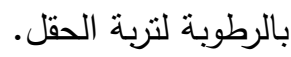

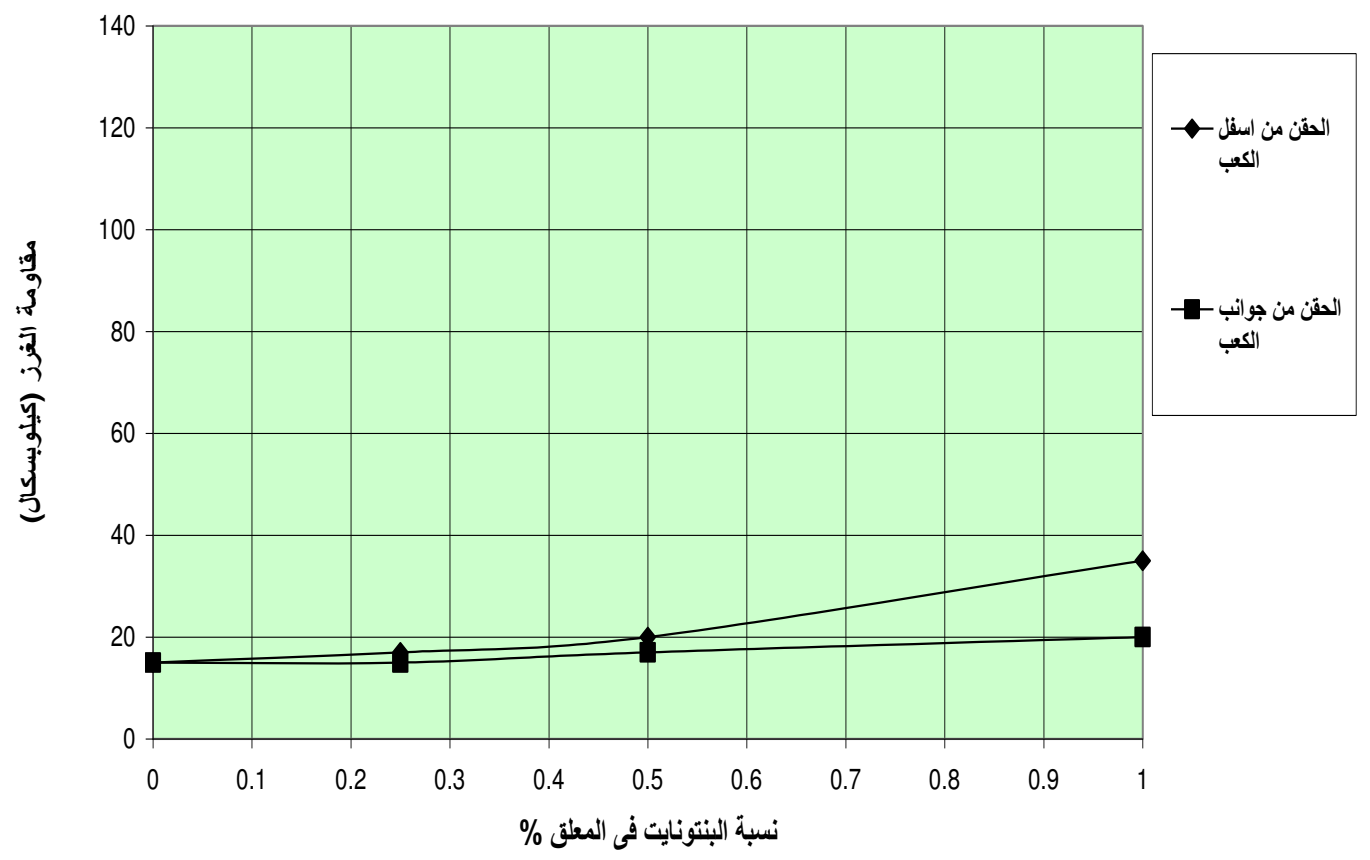

شكل (1) مقاومة الغزز للكثبان الرملية بعد مرور 3 ايام للعلاج من اسفل ومن جوانب كب الحقن عذد نسب مختلفة للبنتونايت 


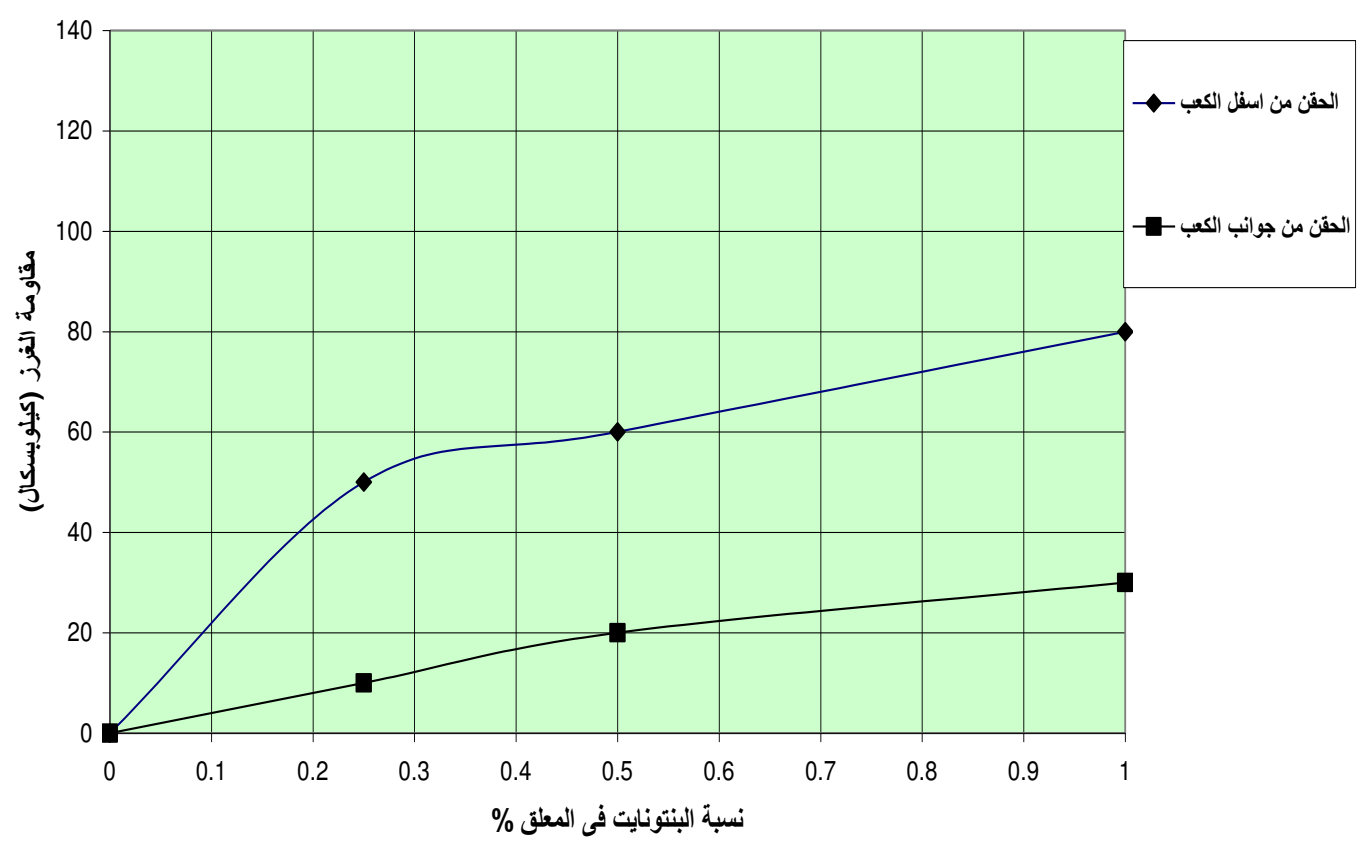

شكل (2) مقاومة الغرز للكثبان الرملية بعد مرور 10 ايام للعلاج من اسفل ومن جو انب كب الحقن عذ نسب مختلفة للبنتونايت

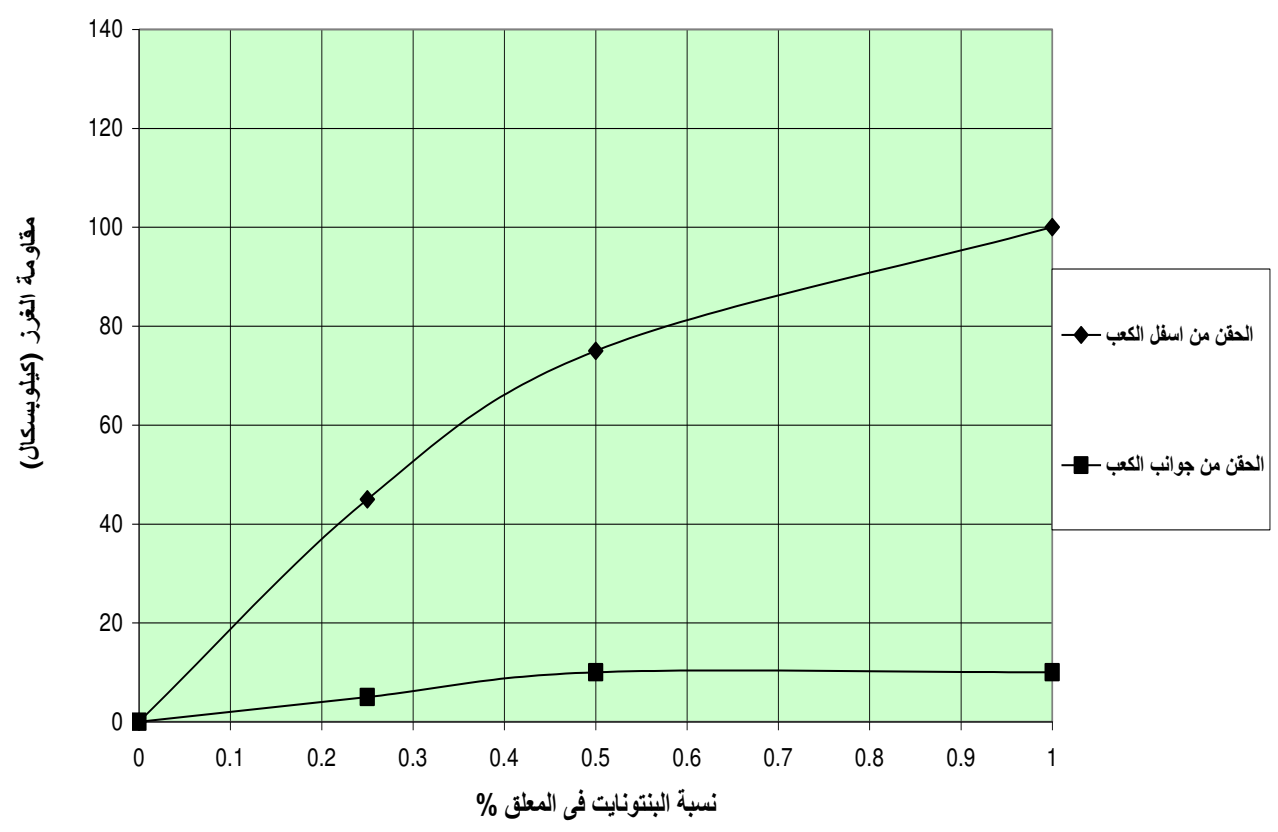

شكل (3) مقاومة الغزز للكثبان الرملية بعد مرور 30 يوم للعلاج من اسفل ومن جوانب كب الحقن غذل نسب مختلفة للبنتونايت 


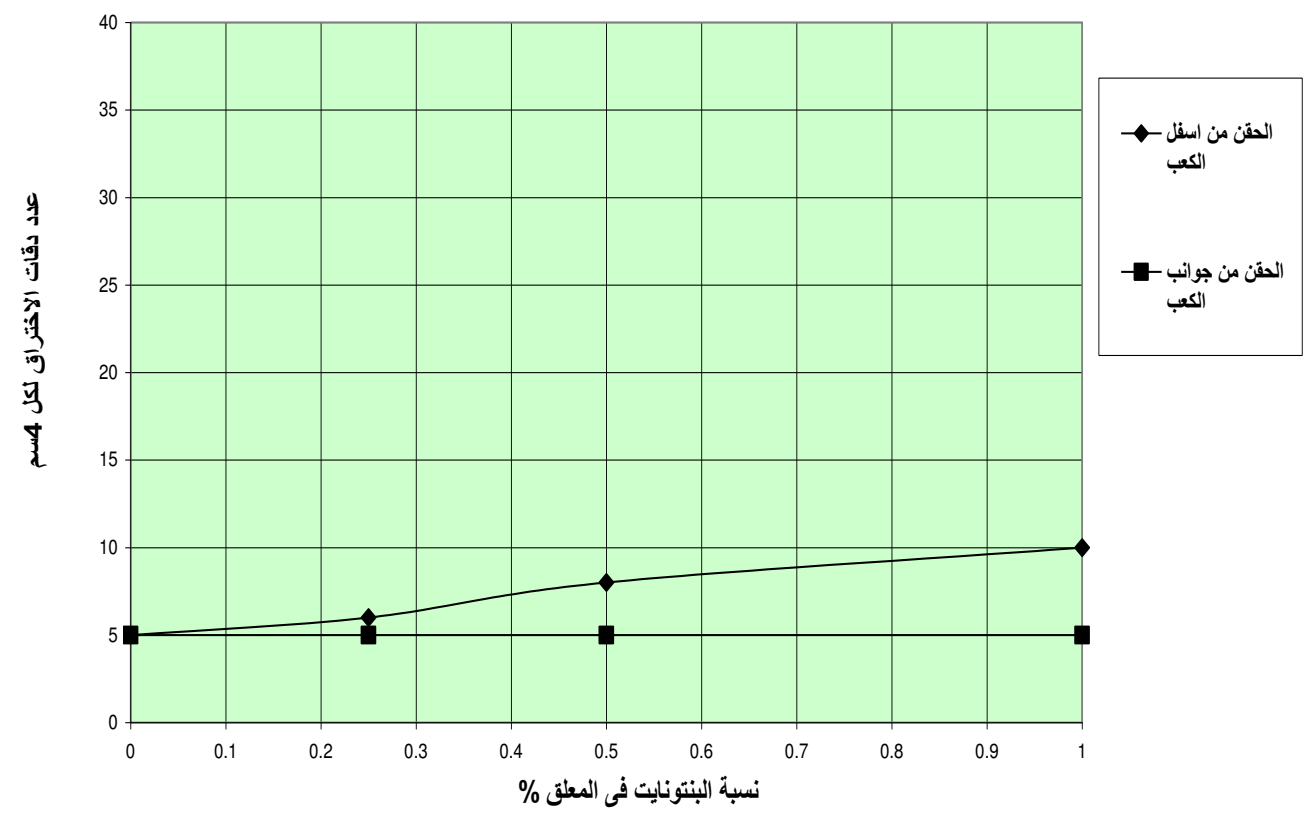

شكل (4) عدد دقات الاختراق للكثبان الرملية بعد مرور 3 ايام للعلاج من اسفل ومن جوانب كب الحقن عند نسب مختلفة للبنتونايت

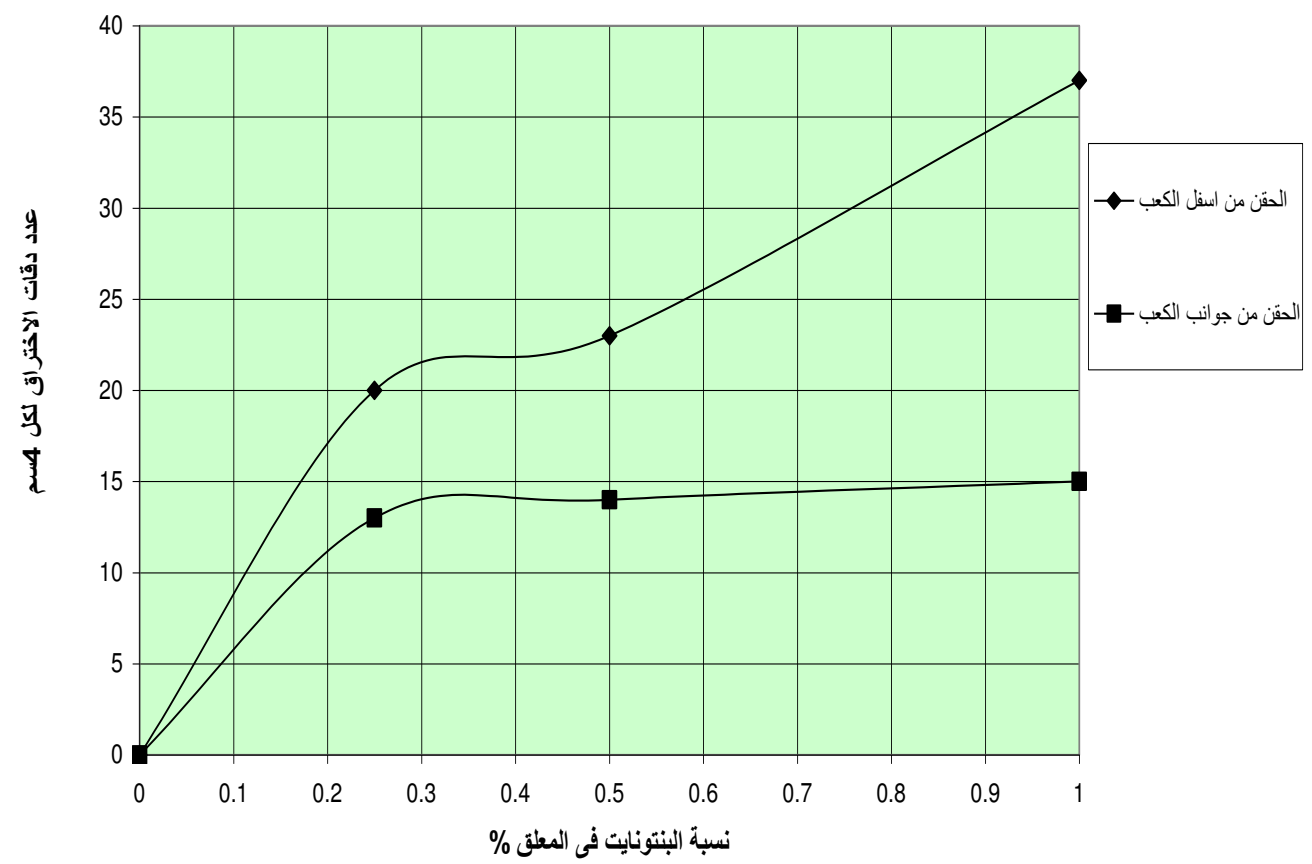

شُكل (5) عدد دقات الاختراق للكثبان الرملية بعد مرور 10 ايام للعلاج من اسفل ومن جوانب كب الحقن عثد نسب مختلفة للبنتونايت 


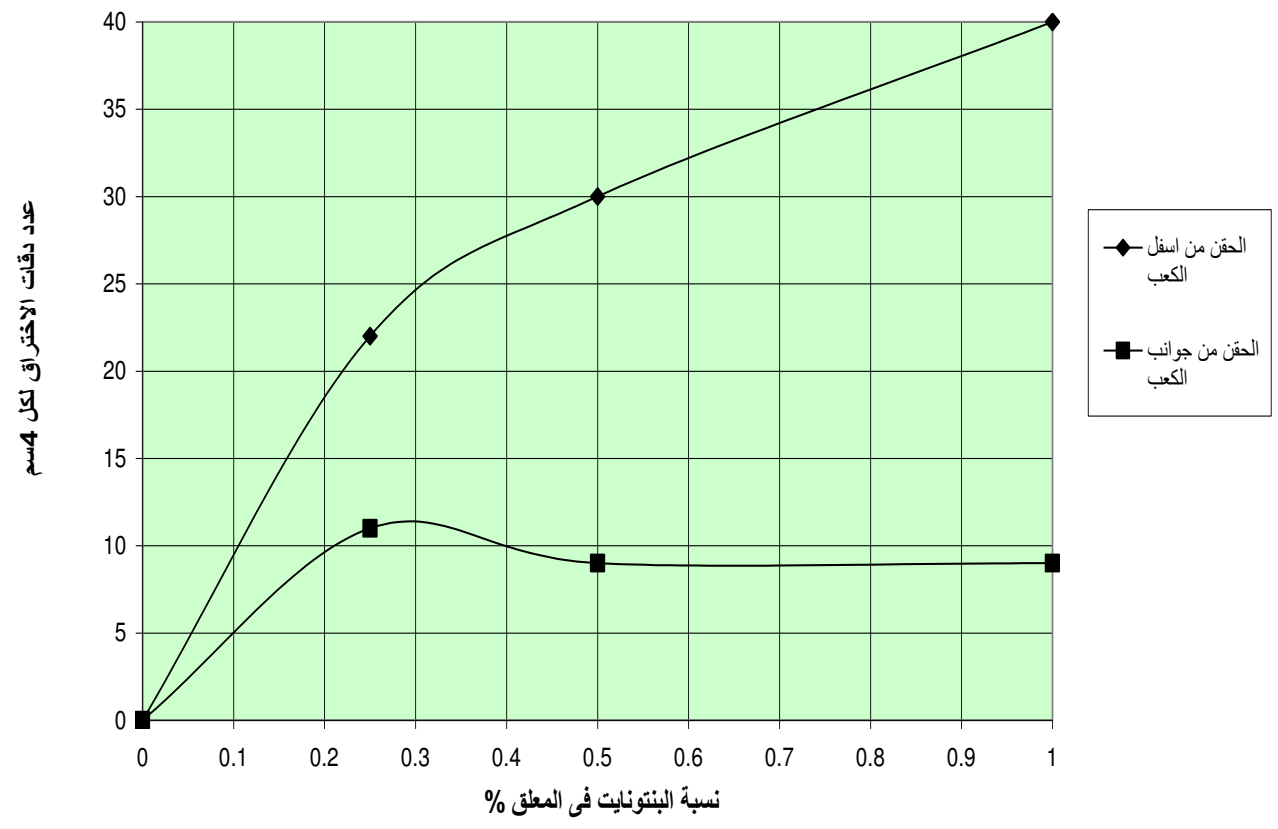

شكل (6) عدد دقات الاختراق للكثبان الرملية بعد مرور 30 يوم للعلاج من اسفل ومن جوانب كب الحقن عثد نسب مختلفة للبنتونايت

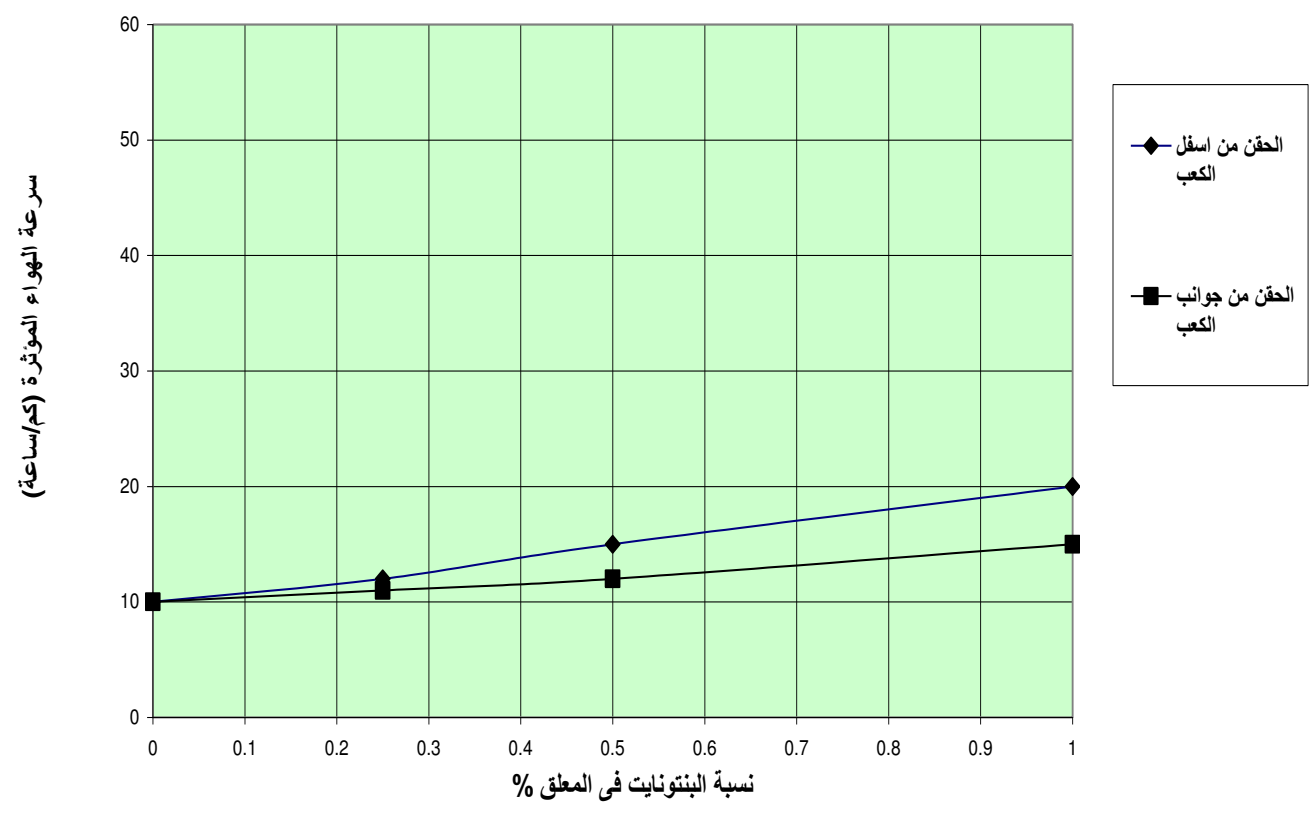

شكل (7) سرعة الهواء المؤُرة على الكثبان الرملية بعد مرور 3 أيام للعلاج من اسفل ومن جوانب كب الحقن عذد نسب مختلفة للبنتونايت 


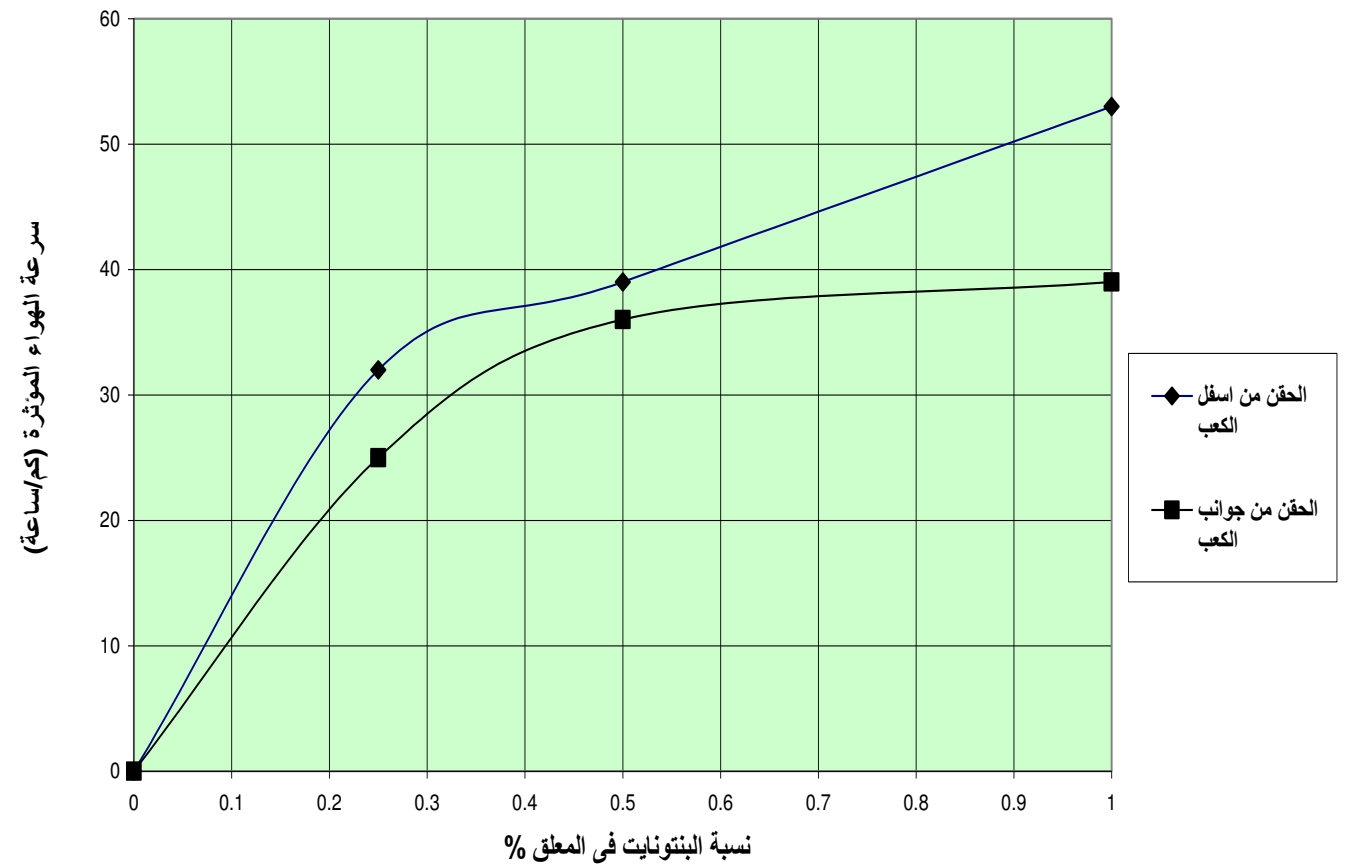

شكل (8) سرعة الهواء المؤثرة على الكثبان الرملية بعد مرور 10 أيام للعلاج من اسفل ومن جوانب كب الحقن عذد نسب مختلفة للبنتونايت

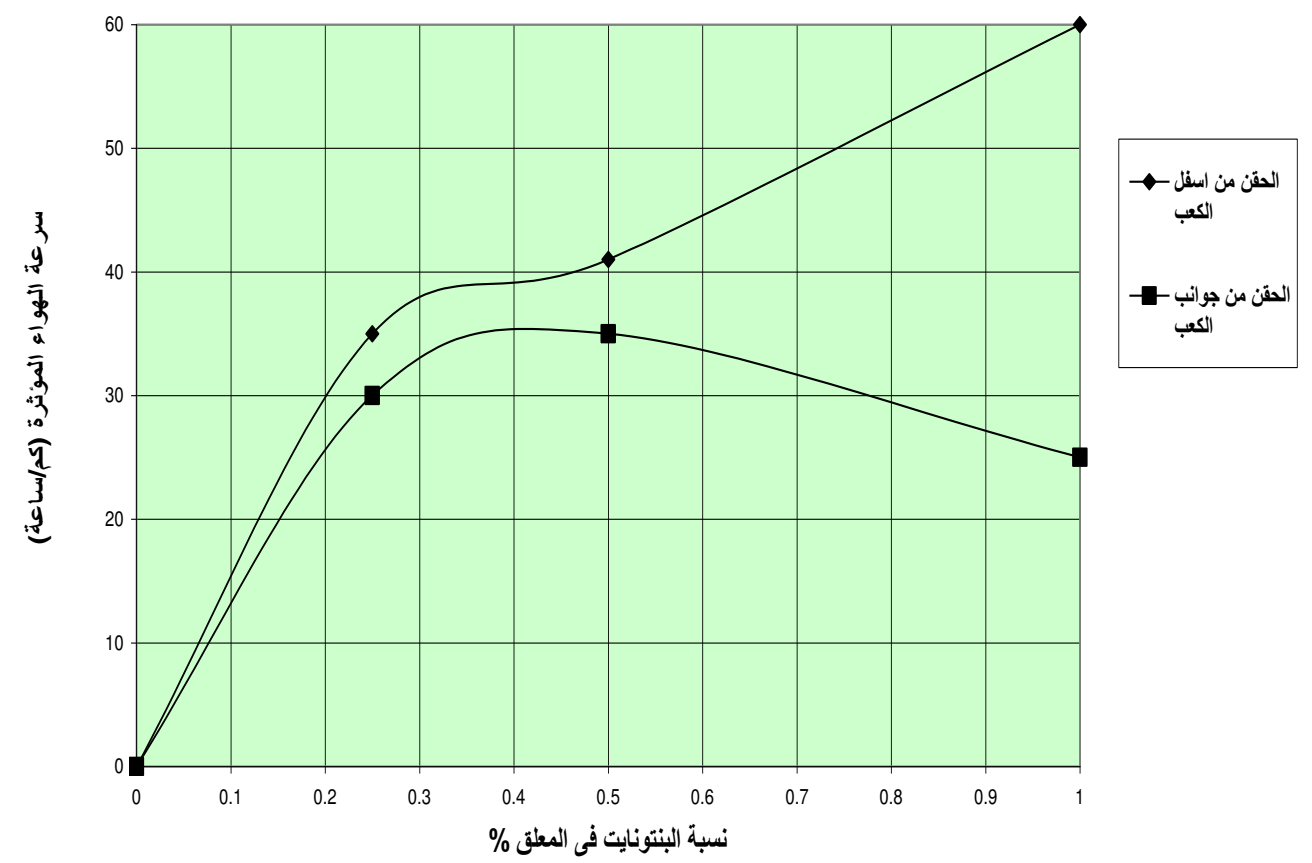

شكل (9) سر عة الهواء المؤثرة على الكثبان الرملية بعد مرور 30 يوم للعلاج من اسفل ومن جوانب كب الحقن عذد نسب مختلفة للبنتونايت 


\section{5- المقارنة بين طريقتى الحقن من أسفل ومن جوانب كعب الحقن بمعلق البنتونايت}

تتضح نتائج قياس الخواص الهندية لطريقتي الحقن بالأثكال (10 - 12). حيث أنه بعد مرور 30 يوم من العلاج لوحظ استمرار الزيادة في تحسن الخواص الهندسية وذلك فقط باستخدام الحقن من أسفل

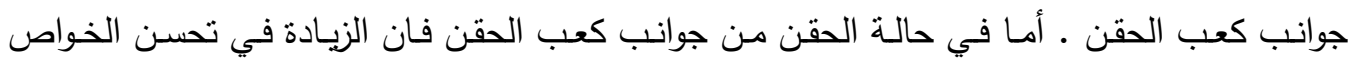

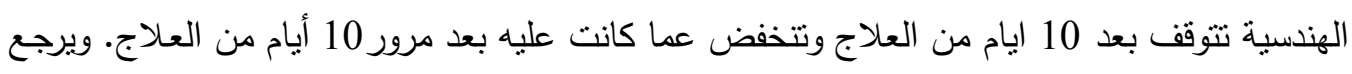

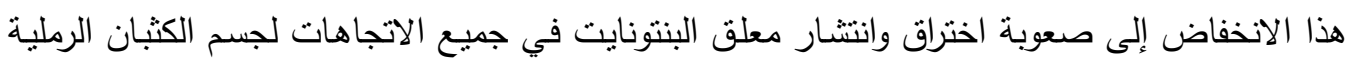
في حالة الحقن من جوانب الكعب فقط. ويمكن تلخيص النتائج التى تم الحصول عليه التيا بعد مرور 30 يوم وبتركيز 1\% بنتونايت فى النقاط النالية:

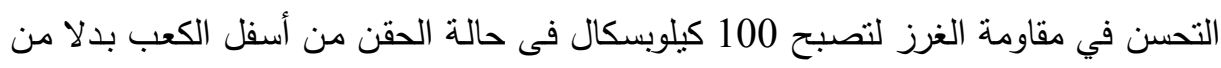

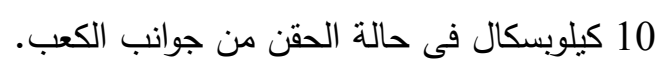
التحسن فى عدد دقات الاختراق ليصبح 40 دقة لكل 4سم فى حالة الحقن من أسفل الكعب بدلا من 10 دقه فى حالة الحقن من جوانب الكعب.

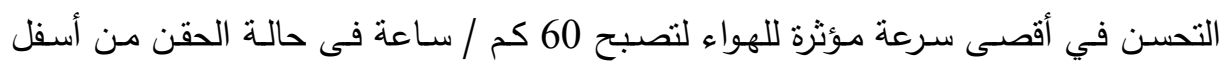
الكعب بدلا من 25 كم/ ساعة فى حالة الحقن من جوانب الكعب.

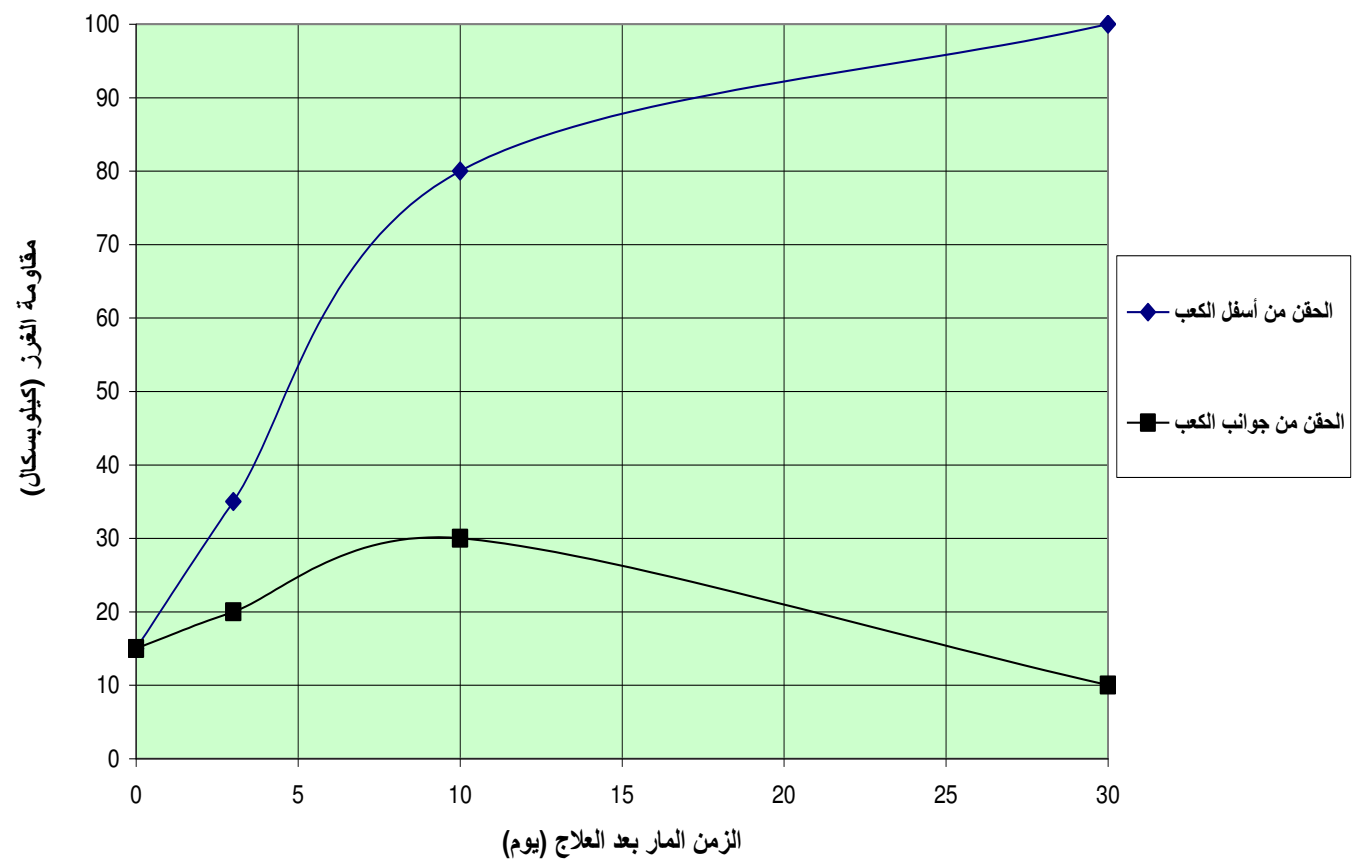

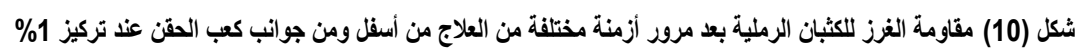
بنتونايت 


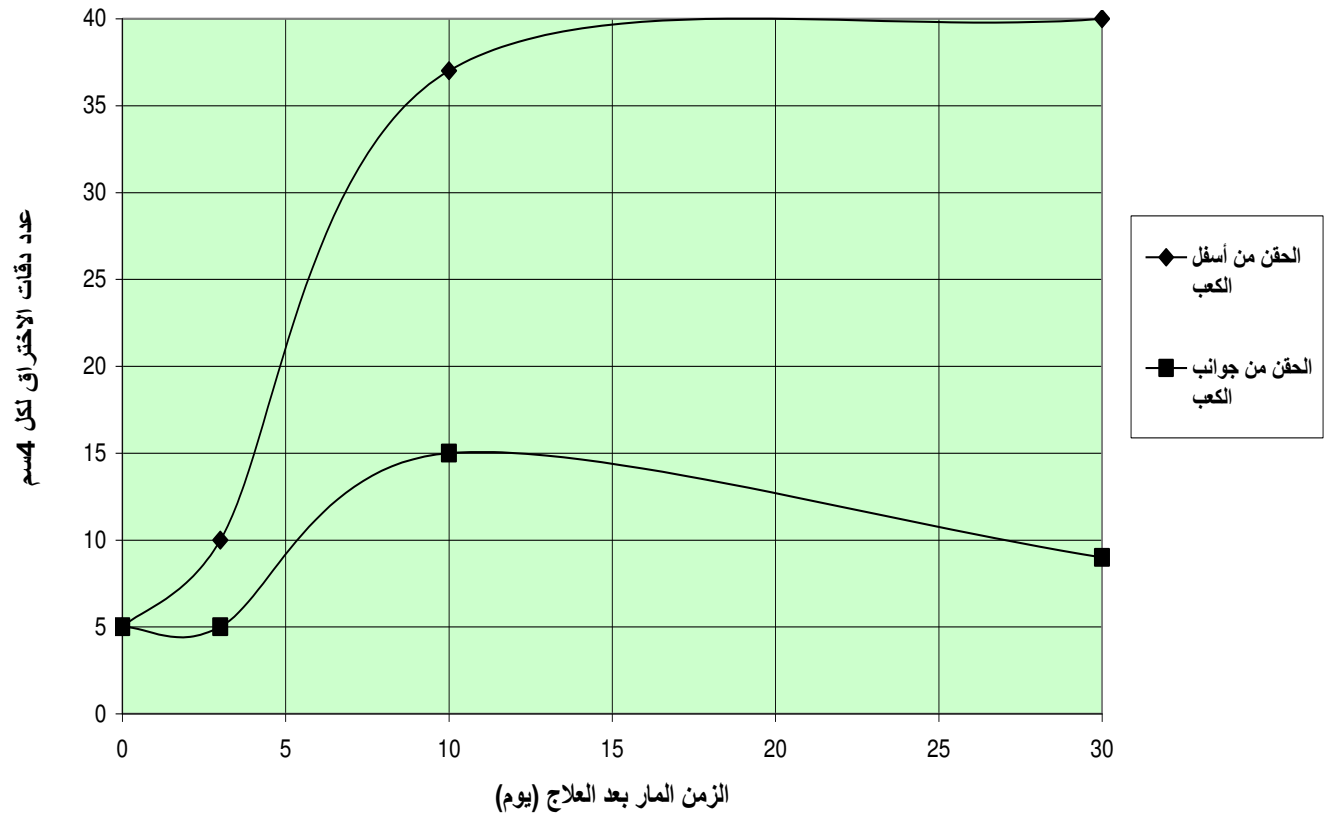

شكل (11) عدد دقات الاختراق للكثبان الرملية بعد مرور أزمنة مختلفة من العلاج من أسفل ومن جوانب كب الحقن عند تركيز 1\% بنتونايت
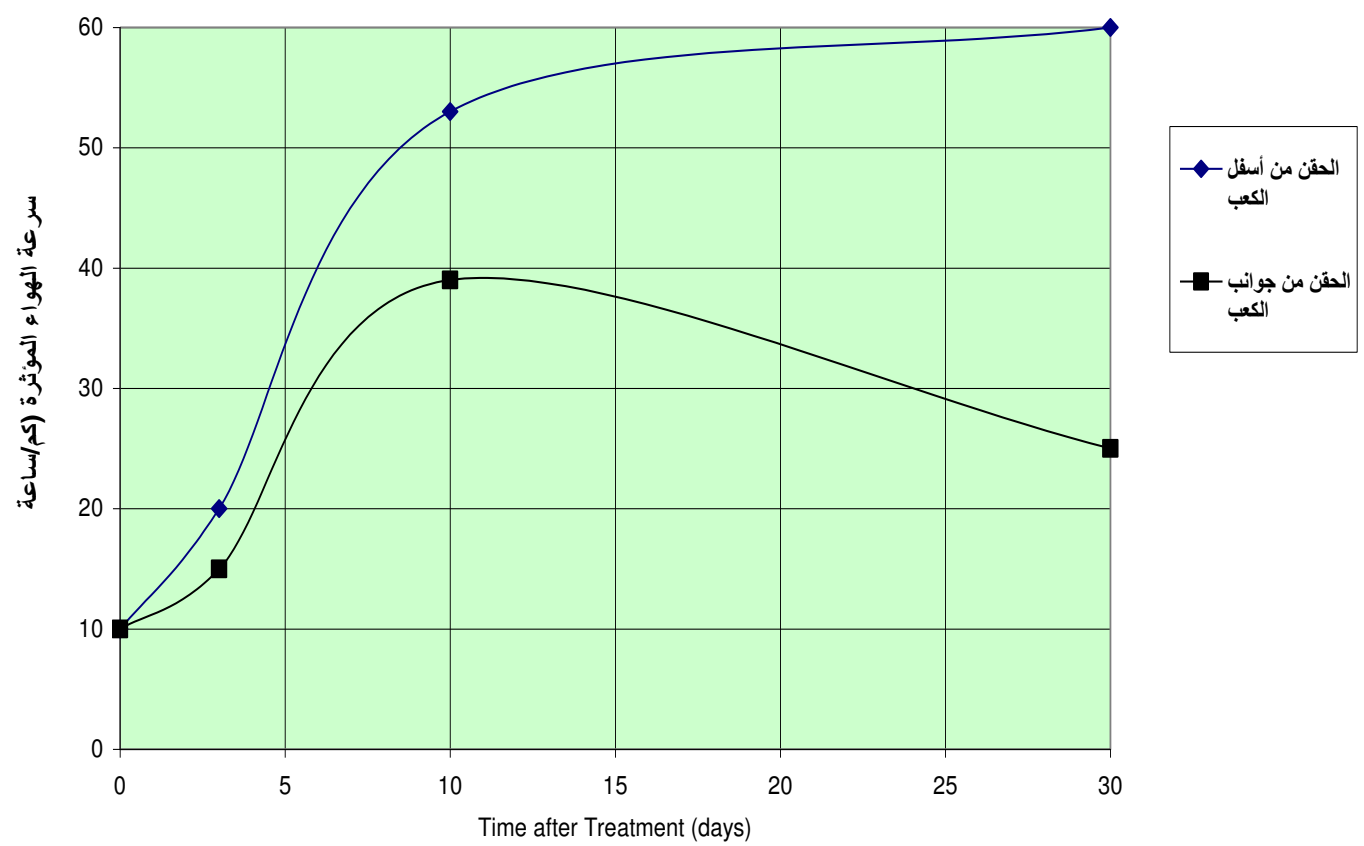

شكل (12) سرعة الهواء المؤثر للكثبان الرملية بعد مرور أزمنة مختلفة من العلاج من أسفل ومن جوانب كب الحقن عذ بـد تركيز 1\% بنتونايت 


\section{6- الخلاصة والتوصيات}

من النتائج والتحليلات السـابقة يتضـح لنـا أن طريقة الحقن من أسفل كعب الحقن بمعلق البنتونايت (بتركيز 1\% فى معلق البنتونايت) أعطت نتيجة أفضل في تحسن الخواص الهندسية لعلاج الكثبان الرملية مقارنة باستخدام الحقن من جوانب كعب الحقن ، وذلك بعد مرور 30 يوم من العلاج ، وكانت

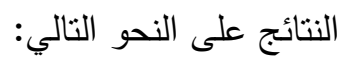

التحسن فى مقاومة الغرز لتصبح 100 كيلوبسكال فى حالة الحقن من أسفل كعب الحقن بدلا

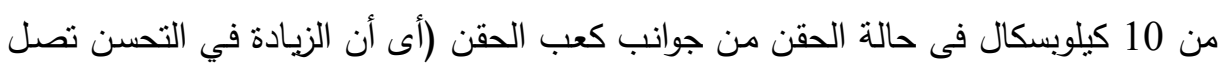
الى 3.50 مقدار القيمة قبل العلاج).

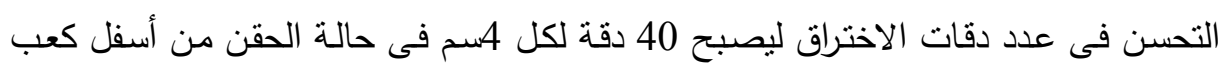

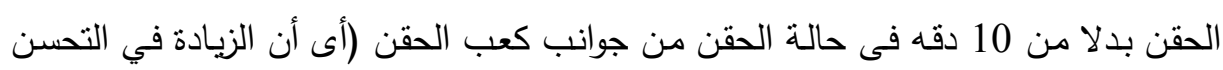
تصل الى 4 أضعاف القيمة قبل العلاج).

التحسن في أقصى سرعة مؤثرة للهواء لتصبح 60 كم / ساعة فى حالة الحقن من أسفل كعب

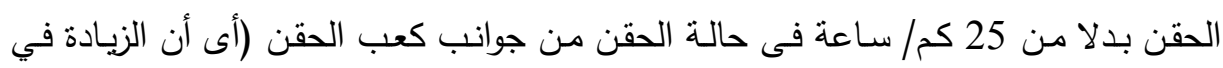
التحسن تصل إلى ضعف القيمة قبل العلاج).

شكر وتقدير:

يتقدم المؤلفون بالثكر والثقدير لمدينـة الملك عبدالعزيز للعلوم والثقنيـة وكذللك عمـادة البحث العلمي بجامعة الملك عبدالعزيز للاعم المادي والمعنوي لهذا البحث.

\section{REFERENCES}

1. Abahussain, A. A., Abdu, A. S., Al-Zubari, W. K., El-Deen, N. A., and AbdulRaheem, M. (2002). Desertification in the Arab region: analysis of current status and trends. Journal of Arid Environments, 51:521-545.

2. Al Sanad, H.A., Ismael, N.F. and Nayfeh, A.J. (1993). Geotechnical properties of dune sands in Kuwait, Engineering Geology, 34 (1-2), 45-52.

3. Armbrust, D.V. and Lyles, L. (1975). Soil stabilizers to control wind erosion, Soil Conditioners, 7, 77-82.

4. ASTM, (1982) American Society for Testing Materials. ASTM Stanards, Part 19, Phildelphia, Pa.

5. http://www.feedo.net/Environment/Desertification/Desertification.htm

6. http://www.kenanaonline.com/page/3409

7. http://www.sotaliraq.com/irq/article_(2004),_02_22_0128.html

8. http://www.amwaj.org.il/geography/dune/enter.html

9. http://www.alsabaah.com/paper.php?source=akbar\&mlf=interpage \&sid=21817

10. http://library.gcc-sg.org/Arabic/Books/Book4/book2chap1.htm 
11. Gillott, J.E. (1988). Clay in engineering geology Elsevier, Amsterdam, 226 pp.

12. Marcuson and Bieganousky, (1977). New York Standards and Specifications.

13. British Standard Institution 5930 (1981). Code of Practice for site investigation.

14. Atkinson, W.J. (1973). The coastal dune system: its management for stability and protection, 1st Australian Conference on Coastal and Ocean Engineering, Sydney, 131-134.

15. Azizov, A. (1975). Cement-sand mixture cellular mechanical screen, Problems of Desert, Development, (1), 85-89.

16. Chen, E.N. (1988). Foundation on expansive soils, Elsevier, Amsterdam, 465pp.

17. Das, B.M., (1982). Soil Mechanics laboratory manual. Engineering Press, San Jose, Calif 505pp.

18. Grim, R.E., (1968). Clay mineralogy. Mc. Graw-Hill Book Company Inc. pp 100-250.

19. Lambe, T.W.,(1951). Soil testing for engineers. Wiley Eastern Limited, New Delhi, 80-81.

20. Marcuson, W.F. and Bieganousky, (1977). SPT and relative density in coarse sands, ASCE j. 103,;GT11.

21. New York Standards and Specifications, For Erosion and Sediment Control, 2005, 3.40-3.47

22. US Army Corps of Engineers, (1987). " Dust Control for Roads, Airfields, and Adjacent Areas", Technical Manual, ARMY TM 5-830-3.

23. Watson, A. (1990). The control of blowing sand and mobile desert dunes. In, Techniques for Desert Reclamation (Ed. A.S. Goudie). John Wiley, London, pp. 35-85. 